\title{
PARIWISATA SYARIAH: SUATU KONSEP KEPERCAYAAN DAN NILAI BUDAYA LOKAL DI DAERAH PEDALAMAN PILUBANG, PAYAKUMBUH, SUMATERA BARAT
}

\section{HALAL TOURISM: A VALUE OF LOCAL WISDOM AND BELIEF CONCEPT IN RURAL AREA PILUBANG PAYAKUMBUH, WEST SUMATERA}

\author{
Mila Falma Masful \\ (mila.falma88@gmail.com)
}

(Program Studi Ilmu Komunikasi, FIKOM, Universitas Sahid Jakarta)

\begin{abstract}
Abstrak
Sumatera Barat banyak dikunjungi wisatawan pada hari-hari besar seperti Idul Fitri, Natal dan Tahun Baru, yang mana mereka datang ke tempat-tempat wisata, seperti Pantai Padang dan Pulau Pasumpahan. Ada beberapa tempat wisata yang terkenal, yaitu Lembah Harau dan Pemandian Batang Tabik. Akan tetapi belakangan ini, sekitar lima tahun, Desa Pilubang, sebuah desa kecil di Payakumbuh, menawarkan sesuatu yang berbeda dan menarik bagi para wisatawan, yakni perjalanan syariah. Konsep ini diyakini muncul dari nilai-nilai Islam dan kearifan lokal yang dicampur menjadi suatu tujuan pariwisata. Dengan tidak menghilangkan esensi dari lokasi pariwisata yang sejatinya tidak Islami, tetapi sebenarnya dapat meningkatkan nilai jual dan ketertarikan bagi paket perjalanan pariwisata. Pilubang Resort sendiri menawarkan pemandangan alam yang indah dan eksotis, penduduk lokal yang ramah, serta situs budaya dengan aturan adat didalamnya.
\end{abstract}

Kata Kunci: Pariwisata Syariah, Kearifan Lokal, Sumatera Barat

\begin{abstract}
West Sumatra have the most visitors on the big day such as Ied Fitr, Christmas and New Year who would come to area attractions such as Padang Beach. Pulau Pasumpahan that also rise sharply. Some of the famous tourist attractions are the Harau Valley and Pemandian Batang Tabik. But lately, about 5 years, Pilubang village, a small village in Payakumbuh offers something different and interesting to the tourists, the sharia travelling. This concept is believed to emerge as Islamic values and local wisdom are mixed into a tourist destination that will demand a lot of circles. By not losing the essence of this area as a village which is very un-Islamic and habitual but actually makes the sale value and attractiveness in the field of travel. Pilubang Resort itself offers a beautiful natural scenery and exotic, local people were friendly, as well as sites with custom rules included therein.
\end{abstract}

Keywords: Sharia Tourism, Local Wisdom, West Sumatera

\section{Pendahuluan}

Secara geografis, Kota Payakumbuh terletak pada posisi $00^{\circ}-10^{\circ}$ sampai dengan $0^{\circ}-17^{\prime}$ LS dan $100^{\circ}-35^{\prime}$ 'sampai dengan $100^{\circ}-48^{\prime}$ BT. Tercatat memiliki luas wilayah $+80,43 \mathrm{Km}^{2}$ atau setara dengan 0,19 persen dari luas propinsi Sumatera Barat dan berbatasan langsung dengan lima kecamatan di Kabupaten Lima Puluh Kota.
Keadaan topografi Kota Payakumbuh bervariasi antara daratan dan berbukit dengan ketinggian 514 meter diatas permukaan laut. Suhu udara ratarata $26^{\circ}$ Celcius dengan kelembaban udara berkisar antara 45 persen sampai 50 persen.Bila dilihat dari segi penggunaan tanah 34,45 persen tanah di Kota Payakumbuh merupakan tanah sawah, dan sisanya 63,3 persen berupa tanah kering. 
Tanah kering ini sebagian besar dimanfaatkan untuk bangunan sebesar 32,59 persen dan untuk usaha pertanian sebesar 32,42 persen, serta sisanya berupa tanah untuk hutan negara, semak belukar, dan lain-lain.

Letak Kota Payakumbuh sangat strategis bila dilihat dari segi lalu lintas angkutan darat Sumbar-Riau. Kota Payakumbuh meruakan pintu gerbang masuk dari arah Pekan Baru menuju kotakota penting di Propinsi Sumatera Barat. Berbagai jenis angkutan penumpang dan barang sangat ramai melewati kota ini pada waktu siang maupun pada malam hari. Jarak kota Payakumbuh ke kota Pekan Baru $188 \mathrm{~km}$ dan dapat ditempuh selama \pm 4,5 jam perjalanan dengan angkutan pribadi, sedangkan jarak ke kota padang sejauh $124 \mathrm{~km}$, dapat ditempuh dengan kendaraan pribadi selama $\pm 2,5$ jam perjalanan (http://payakumbuhkota.go.id/tentangpayakumbuh/geografis/).

Dinas Kebudayan dan Pariwisata lahir dari Perda Nomor 6 Tahun 2008, Tentang Pembentukan Organisasi dan Tata Kerja Dinas Daerah mempunyai Visi "Terwujudnya Kabupaten Lima Puluh Kota sebagai daerah tujuan wisata andalan di Sumatera Barat, dengan pembangunan kebudayaan dan pariwisata yang beridentitas adat dan agama, untuk kesejahteraan masyarakat". Misi yang diemban oleh Dinas Kebudayaan dan Pariwisata adalah sebagai berikut 1 . Melakukan Pelestarian Sejarah dan Pengembangan Kebudayaan yang berlandaskan adat basandi syarak, syarak basandi kitabullah, 2. Melakukan pengembangan destinasi dan pemasaran Pariwisata yang berdaya guna yang berbasis Nagari dan masyarakat, 3. Melakukan pengembangan sumberdaya kebudayaan dan pariwisata, serta 4 . Membangun jaringan kerjasama kebudayaan dan pariwisata.

Kabupaten Lima Puluh Kota, mempunyai beberapa kelompok jenis wisata yakni : Berdasarkan Objek Wisata yang dijual, Lima Puluh Kota, memiliki 4 (empat) jenis objek yakni Wisata Alam (33 objek) yang menjadi andalan 3 objek, adalah Lembah Harau, Kapalo Banda dan Batang Tabik. Wisata Budaya (6 Objek) yang menjadi andalan seperti Rumah Gadang Sungai Baringin, Rumah Ukiran Cino di Simalanggang, Perkampungan Belubus, Perkampungan seribu Gonjong di Koto Tinggi Kecamatan gunuang Omeh. Wisata Sejarah (9 Objek) yang menjadi andalan seperti Makam Pahlawan Situjuah, Tugu PDRI di Halaban, Tugu PDR Koto Tinggi, Rumah Tua Tan Malaka, dan Wisata Arkeologi (4 Objek) seperti Komplek Menhir di Koto Tinggi Maek, Kecamatan Bukik Barisan, komplek menhir Belubus, Kecamatan Guguak.

Berdasarkan tujuan berwisata, Kabupaten Lima Puluh Kota memiliki 4 (empat) kategori yakni: Pariwisata untuk menikmati perjalanan (7 objek), Pariwisata untuk Rekreasi (24 Objek), Pariwisata untuk kebudayaan (19 objek) dan pariwisata untuk olahraga ( 2 objek). Maka dari uraian tersebut pada masa sekarang ini dkembangkanlah potensi wisata kebudayaan di nagari Pilubang kecamatan Harau, Lima Puluh Kota. Desa kecil yang mengusung konsep agama Islam dan budaya setempat sebagai nilai jual wisatanya Sepanjang jalan desa Pilubang terdapat beberapa papan yang bertuliskan Negeri Masa Depan yang artinya suatu tempat yang menawarkan keindahan, kedamaian, pesonanya dan daya tarik dinding-dinding bukit batu bewarna bak benteng. Karakternya hampir sama dengan Harau. Namun di Pilubang hamparan pertanian sawah banyak kita jumpai sepanjang jalan menuju tempat wisata yang memang cukup terpencil ini, yaitu Pilubang Resort.

\section{Metodologi}

Suatu penelitian kualitatif dieksplorasi dan diperdalam dari suatu fenomena social atau suatu lingkungan 
social yang terdiri atas pelaku, kejadian, tempat dan waktu. Penelitian kualitatif merupakan penelitian yang menggunakan latar alamiah, dengan menafsirkan fenomena yang terjadi dan dilakukan dengan jalan melibatkan berbagai metode yang ada. Metode penelitian eksploratif adalah penelitian yang bertujuan untuk mematakan suatu objek secara relatif mendalam atau dengan kata lain penelitian eksploratif adalah penelitian yang dilakukan untuk mencari sebab atau halhal yang mempengaruhi terjadinya sesuatu dan dipakai manakala kita belum mengetahui secara persis dan specifik mengenai objek penelitian kita. Peneliti mengungkapkan penelitian eksploratif ini secara kualitatif. Sugiyono (2007: 49) menyatakan:

"dalam penelitian kualitatif tidak menggunakan istilah populasi tetapi dinamakan social situation atau situasi sosial yang terdiri dari tiga elemen yaitu: tempat, pelaku dan aktifitas. Pada situasi sosial atau obyek penelitian ini penelitian dapat mengamati secara mendalam aktivitas orang-orang yang ada pada tempat tertentu." Sugiyono (2007: 50) menyatakan bahwa sebenarnya dalam obyek penelitian bukan semata-mata pada situasi sosial yang terdiri atas tiga elemen tersebut, tetapi bisa berupa peristiwa alam, kendaraan dan lain-lain.

Adapun pendekatan penelitian yang digunakan peneliti dalam penelitian ini adalah pendekatan induktif, yaitu suatu pendekatan dengan mengambil suatu kesimpulan secara umum dari fakta-fakta nyata yang ada di lapangan. Induktif merupakan cara berpikir, di mana ditarik kesimpulan yang bersifat umum dari berbagai kasus yang bersifat individual. Penarikan kesimpulan secara induktif dimulai dengan menyatukan pernyataanpernyataan yang bersifat umum.

Pada penelitian ini peneliti ingin mengetahui dan mengeksplorasi bagaimana awal munculnya wisata berkonsep syariah di Desa Pilubang ini dan peneliti ingin mengetahui secara mendalam mengenai pengaruh nilai budaya dan agama dalam pengembangan wisata syariah ini. Pengamatan juga sangat perlu dilakukan agar dapat dijadikan suatu pembanding dengan hasil wawancara. Setelah melakukan penelitian diperoleh suatu kesimpulan umum. Oleh peneliti sendiri, ini merupakan penelitian kualitatif deskriptif dengan mewawancarai pengelola resort, warga setempat dan ikut mengamati seperti apa daerah Pilubang ini.

\section{Hasil dan Pembahasan}

Beberapa temuan dalam studi ini, diantaranya:

1. Agama Islam dan Adat

Minangkabau

Kedatangan agama Islam ke Minangkabau berbeda dengan kedatangan agama Hindu dan Budha. Kedatangan Islam ke Minangkabau menjadi rahmat (kasih sayang) bagi masyarakat Minangkabau. Hal ini disebabkan karena masuk dan berkembangnya Islam di tengah adat yang ada sebelumnya, sejalan dengan pola yang telah ditempuh Nabi Muhammad SAW sebagai pembawa ajaran Islam, waktu masuk ke tanah Arab sebelumnya juga telah diatur oleh tatanan adat. Pola yang dimaksud adalah sebanyak mungkin menerima dan menyerap adat yang telah ada dan disatukan dengan ajaran agama yang datang kemudian.

Islam membawa tatanan tentang apa yang harus diyakini oleh umat atau yang disebut akidah dan tatanan tentang apa yang harus mereka amalkan, yang disebut dengan syari'ah atau syara', yang menyangkut dengan akidah ini terutama tentang ketuhanan. Adat Minangkabau tidak menampakkan bentuknya yang nyata dan hanya mendasarkan kepada alam nyata.

Setelah Islam masuk adat Minangkabau diarahkan secara perlahanlahan kepada keyakinan akan alam ghaib (alam akhirat) sebagai tujuan hidup manusia. Jika pada mulanya adat 
Minangkabau hanya mengakui alam nyata saja dan dengan pengaruh Islam akhirnya berubah kepada pengakuan akan adanya alam ghaib (alam akhirat) sebagai tujuan akhir untuk bertemu dengan sang Pencipta alam nyata ini yaitu Allah SWT (http://ejurnalteologia.co.id/2011/12/traktat -marapalam-adat-basandi-syara.html).

Pilubang Resort merupakan suatu kawasan kecil yang terletak di pedesaan Pilubang, Kota Lima Puluh Kota, Sumatera Barat. Bermula dari seoarang pengusaha bernama Bapak Danish Hermawan asal Yogyakarta beristrikan wanita asli Payakumbuh yang ketika pulang ke kampung halaman istri beliau lalu sekitar tahun 2008 tertarik membeli sebidang tanah seluas empat Hektar di desa Pilubang. Maka pada saat itu terniatlah oleh Bapak Danish untuk membangun penginapan asri yang diperuntukkan untuk kepentingan pribadi beliau. Awalnya bukan penginapan yang dibangun beliau, tetapi perkebunan buah Naga sebagai wisata buah nantinya. Namun sayang, dikemudian harinya kebun ini tidak terurus dengan baik dikarenakan hewan monyet sering merusak dan memakan buah naga. Akhirnya beliau pun beralih membangun resort pribadi.

Mulai pada tahun 2009, Pilubang Resort mulai dibuka untuk umum dengan alasan banyak relasi Bapak Danish dari luar kota seperti dari Pekanbaru tertarik untuk berwisata ke Sumatera Barat dan menikmati suasana alam. Terdapat 11 kamar yang dibangun secara astri seperti Cottage di tempat lain. Pada tahun 2010 2012 rupanya banyak wisatawan yang berkunjung dan masyarakat setempat yang mengetahui hal ini agak kurang menyukai karena beberapa tamu yang datang kadang berpakaian tidak rapi dan sering terdengar suara keramaian yang cukup mengusik warga desa sekitarnya. Oleh karena itu sekitar tahun 2012 disepakatilah beberapa ketentuan yang wajib diikuti oleh pemilik dan pengunjung wisata Pilubang Resort. Adapun ketentuan ini lahir dari nilai adat dan agama Islam yang ada di Pilubang, dengan harapan jika masyarakat dan pendatang bisa mengikuti aturan dan larangan dengan baik maka terciptalah kedamaian dan keridhoan dari Allah SWT sang Maha Pencipta. Seperti yang diketahui, masyakarat desa di Sumatera Barat pada umumnya, dan Pilubang pada khususnya merupakan penganut agama Islam. Selain itu, menurut Edy (2002), masyarakat menjunjung tinggi nilai adat yang berbunyi "Adat Basandi Syarak, Syarak Basandi Kitabullah", yang artinya adalah adat yang didasarkan oleh syariat agama Islam yang syariat tersebut berdasarkan pada Al - Quran dan Hadist. Adat berarti peraturan, Sandi artinya landasan, Syarak artinya kumpulan hukum-hukum islam, Kitabullah berarti kumpulan wahyu-wahyu Allah yang diturunkan kepada rasul-rasul tertentu. ABS-SBK artinya adalah aturan-aturan adat Minangkabau takluk kepada syariatsyariat islam yang dibawa oleh Nabi Muhammad SAW.

2. Konsep Wisata Syariah

According to one very authoritative book entitled 'The Lawful and the Prohibited in Islam', which was written by Sheikh Yusuf al-Qaradawi, a globally-respected Islamic scholar and chairman of the International Union of Muslim Scholars, the term Halal is defined as "That which is permitted, with respect to which no restriction exists, and the doing of which the law-giver, Allah, is allowed". Therefore, Halal term means 'permissible' according to Islamic teaching (Sharia law). Halal is also one of five action (alahkam al-khamsah) that categorizes the morality of human action in Islam, others being Fard (compulsory), Mustahabb (recommended), Makruh (disliked), and Haram (forbidden) (Faruki, 1966). From Islamic perspective, Halal as defined above refers to any practise or activity in tourism which is 'permissible' according to Islamic teaching 
(http://dx.doi.org/10.1016/j.tmp.2015.12.0082 211-9736).

Menurut salah satu buku berjudul 'The Lawful and the Prohibited in Islam', yang ditulis oleh Sheikh Yusuf alQaradawi, seorang ulama Islam global yang dihormati dan ketua Persatuan Ulama Muslim Internasional, Halal didefinisikan sebagai "yang diizinkan, sehubungan dengan yang tidak ada pembatasan, dan memberlakukan hukum dari Allah, dan diperbolehkan". Oleh karena itu, istilah halal berarti 'diperbolehkan' menurut ajaran Islam (hukum Syariah). Halal juga merupakan salah satu dari lima tindakan (al-ahkam alkhamsah) yang mengkategorikan moralitas tindakan manusia dalam Islam, orang lain menjadi Fard (wajib), Mustahabb (dianjurkan), Makruh (tidak menyukai), dan Haram (dilarang) (Faruki, 1966). Berdasarkan perspektif Islam, Halal sebagai didefinisikan di atas mengacu pada praktek atau kegiatan di bidang pariwisata yang 'diperbolehkan' menurut ajaran Islam. Wisata berkonsep syariah di daerah nagari Pilubang ini sebenarnya bukan tempat wisata resmi yang tercatat di pemerintahan daerah Payakumbuh, tetapi merupakan suatu kawasan kecil yang dijadikan tempat singgahan untuk menikmati alam dan keindahan desa Pilubang. Lalu dikarenakan tempat ini akhirnya diperuntukan untuk umum, maka dibangunlah dan dibukalah kawasan wisata yang memang berkonsep syariah, dengan menjunjung nilai nilai agama Islam dan tentunya nilai adat Minangkabau yang dianut warga dan diterapkan untuk siapapun yang berada dan berkunjung ke Kawasan Laranngan Balirik, Pilubang.

Berikut hasil wawancara dan pengamatan peneliti ketika berkunjung dan bertemu pengelola Resort bernama Anto pada hari Selasa, 26 April 2016, di Pilubang. Pilubang Resort yang sekarang berganti nama menjadi Balirik Larangan Resort.
Balirik dalam bahasa Indonesia diartikan bersusun.

1. Insya Allah ditetapkan menjadi nama baru pengganti "Pilubang Resort Syariah" pada bukan suci Ramadhan $1432 \mathrm{H}$, yakni sebagai satu satunya kawasan resort yang mengharamkan banyak hal demi menjaga kesucian "Kawasan Larangan" di nagari Pilubang Kecamatan Harau Kabupaten Lima Puluh Kota, Sumbar, Indonesia.

2. Prolog, Arti dan Makna

a) Balirik Larangan: secara harfiah arti sederhananya adalah berderet larangan, yakni barisan memanjang sejumlah papan larangan yang berisi tentang segala sesuatu yang dilarang/ diharamkan.

b) Nawaitu: sejak awal niat kami adalah berupaya mengemban amanah atas titipan sementara Yang Kuasa, yatiu berupa sekawasan bentagn alam indah yang sarat dengan beragam kekayaan ini, untuk tetap dijaga, dikelola dan dikembangkan agar mampu menghasilkan banyak manfaat dan kebaikan bagi sesama makhluk ciptaan Allah SWT. Berbekal keyakinan tersebut, semakin meneguhkan nawaitu kami untuk menetapkan kawasan resort ini insyaAllah sebagai "kawasan terlarang" yang mengharamkan setiap bentuk pelangaran dan penistaan terhadap kesucian Tanah Titipan Allah ini.

c) "Kawasan Terlarang": kami menyadari bahwa masih teramat banyak insan insan bertaqwa yang mendambakan suatu tempat wisata yang "bersih", yaitu bebas dari segala hal yang berkonotasi negatif dan bertentangan dengan isi terdalam hati kita. Namun, di era modern sekaran ini ternyata tidak mudah untuk mendapatkannya.

Atas pertimbangan itulah, terbangun niat kami untuk mengelola resort dengan konsep usaha syariah berazaskan kekeluargaan secara eksklusif di khususkan bagi insan yang menghendaki kesucian, kedamaian, dan kesederhanaan, serta kenyamanan dalam balutan suasana sunyi pedesaan yang jauh dari hiruk pikuk dan kebisingan kota. 
Sekaligus kami juga ingin berbagi amanah kepada mereka, untuk bisa menikmati dan mensyukuri beragam keindahan alamiah ciptaan Allah, yang membentagn dalam bingkaian tebing bebatuan tegak dan berdiri kokoh di setiap penjuru kawasan resort.

Kami bersandar pada sebuah keyakinan bahwa siapapun yang berkepentingan langsung maupun tidak langsung terhadap resort, memikul tanggungjawab dan kewajiban yang setara untuk bersama sama menjunjung tinggi amanah Allah dalam menjaga kesucian "Kawasan Terlarang" ini.

Dengan demikian, masing-masing diri sepatutnya mempunyai pola pikir dan cara pandang yang selaras untuk senantiasa saling bahu membahu mencegah siapapu dan apapun yang akan mencederai kesucian dalam kedamaian "Kawasan Terlarang" ini.

d) Terlarang untuk Apa dan Bagi Siapa

Barangkali dan boleh jadi, inilah satu satunya resort di muka bumi yang memiliki jumlah larangan terbanyak dan secara sengaja memajang semua papan larangan di setiap penjuru kawasan resort. Larangan tersebut bisa dicirikan dalam awalan kata: DIHARAMKAN, DILARANG, TIDAK BOLEH, TIDAK DIIJINKAN, TIDAK DIPERKENANKAN, TIDAK DIANJURKAN, dan JANGAN!

Bisa jadi siapapun akan merasa risih dan terbebani oleh banyaknya larangan tersebut. Bahkan akan menilainya sebagai resort yang kolot dan berlebih - lebihan dalam menerapkan aturan mainnya.

Tiga puluh tiga larangan dan diharamkan di seluruh "Kawasan Terlarang" ini adalah:

1. Pasangan pria dan wanita, bukan suami istri yang sah.

2. Minuman Keras/alkohol (bir dan sejenisnya).

3. Narkoba dan sejenisnya.

4. Anjing (semua hewan penyebab najis) dan satwa dilindungi.
5. Berjudi, melalui berbagai cara dan wujudnya.

6. Berpakaian minim/tidak sopan yang mengundang syahwat.

7. Memakan dan meminum tidak halal.

8. Memberikan Identitas Palsu (KTP, Surat Nikah).

9. Sepeda montor menggunakan knalpot yang berisik dan memekakkan telinga.

10. Berpacaran/dan yang mendekati Zina.

11. Pasangan sejenis (Gay/Lesbian) dan atau kejahatan seksual.

12. Mobil yang membunyikan musik/suara keras.

13. Memutar/menyanyikan lagu-lagu House Music dan sejenisnya.

14. Gerakan tarian termasuk olahraga pornografi dan cabul.

15. Tayangan video atau animasi/yang berbau pornografi.

16. Kegiatan Bit'ah dan menjurus syirik (magis, sulap, hipnotis).

17. Menyalakan petasan/kembang api, tanpa ijin terlebih dahulu.

18. Rapat/pertemuan atau diskusi atau yang dapat melawan hukum.

19. Berkata kotor, jorok/mengumpat.

20. Berteriak-teriak atau berbicara keras atau berbuat onar.

21. Bergunking/bergosip/memfitnah/

berkata bohong dan provokasi.

22. Berkelahi, baik secara fisik maupun adu mulut.

23. Menebang/merusak semua pepohonan.

24. Membunuh/berburu hewan dangan cara apapun termasuk satwa liar.

25. Mencoret/grafiti di semua benda (termasuk tebing/pohon).

26. Membuat api unggun selain di tempat yang disediakan.

27. Membuang sampah termasuk puntung rokok dengan sembarangan.

28. Buang air kecil dan BAB ditempat sembarangan. 
29. Mencuri atau mengutil/ memanfaatkan barang - barang yang bukan haknya.

30. Berkendara dengan kencang.

31. Merusak/menjahili semua properti dan papan larangan.

32. Meniru/menjiplak semua ide/konsep yang ada di kawasan resort.

33. Protes terhadap semua larangan di "Kawasan Terlarang" ini.

The concept of halal, meaning permissible in Arabic, is not just being applied to food, but it includes any Shari'ah compliant products ranging from bank dealings to cosmetics, vaccines and in this case, tourism. This means offering tour packages and destinations that are particularly designed for Muslim considerations and address Muslim needs.

As there is no specific definition of Halal tourism, it is mainly perceive a tourism product providing hospitality services that comply with Islamic Law. For example, halal hotels do not serve alcoholic beverages, offer halal certificates for food, wellness facilities for women,prayer room sand, in general, a Muslim-friendly environment

(Geetanjaliramesh Chandra. Halal Tourism: A New Gold Mine for Tourism. International Journal of Business Management \& Research (IJBMR), Vol. 4, Issue 6, Desember 2014, hal. 45-62).

Konsep halal, berarti diperbolehkan dalam bahasa Arab, tidak hanya diterapkan untuk makanan, tapi itu termasuk produk syariah mulai dari transaksi perbankan untuk kosmetik, vaksin dan dalam hal ini, pariwisata. Hal ini berarti paket wisata dan tujuan yang khusus dirancang untuk memenuhi pertimbangan Muslim dan ditujukan untuk kebutuhan para Muslim. Karena tidak ada definisi khusus pariwisata halal, hal ini terutama dirasakan sebagai produk pariwisata yang menyediakan jasa perhotelan yang sesuai dengan hukum Islam. Misalnya, hotel halal tidak melayani minuman beralkohol, menawarkan sertifikat halal untuk makanan, fasilitas kesehatan bagi perempuan, ruang doa dan, secara umum, lingkungan ramah-Muslim.

\section{Penutup}

Berdasarkan hasil penelitian tersebut maka peneliti menalaah beberapa hal mengenai tempat "kawasan terlarang" tersebut:

1. Berawal dari keinginan seorang warga yang memiliki lahan kosong yang bisa dijadikan tempat bersantai, lalu dikarenakan beberapa orang relasi tertarik untuk berkunjung dan menginap, maka dibukalah kawasan ini sebagai tempat wisata.

2. Nilai agama dan adat yang sangat kuat disertakan dalam pembangunan kawasan wisata ini. Hal ini bertujuan agar kehidupan yang damai tercipta di desa ini dan Allah SWT selalu melindungi masyarakat sekitar dan pengunjung yang datang.

3. Walaupun banyak terdapat larangan ketika menginap di Balirik Larangan Resort, tetapi pengunjung selalu mentaati aturan tersebut dengan baik. Pengunjung tetap bisa menikmati wisata dengan leluasa tetapi tidak bebas begitu saja.

4. Kawasan Balirik Larangan biasanya dikunjungi oleh wisatawan yang tahu informasinya melalui mulut ke mulut. Umumnya yang datang menginap dan bermain adalah orang orang yang ingin menikmati sejuknya udara Pilubang dan tenang karena jauh dari kebisingan. Bahkan tidak akan ditemukan fasilitas wisata yang banyak permainan bagus dan kawasan ini pun tidak lah terlalu luas.

5. Pengunjung yang datang biasanya adalah dari perusahaan atau organisasi yang membawa karyawan beserta keluarga untuk berkumpul/gathering.

6. Untuk menambah nilai jual maka pihak pengelola juga menyediakan sarana dan prasarana permainan flying fox, tempat 
bakar ikan, dan pemandian yang airnya langsung dari alam.

Berlandaskan pemaparan di atas maka peneliti mengkaji beberapa hal mengenai wisata syariah ini. Wisata yang sudah dibuka 7 tahun lalu ini sempat mengalami beberapa kendala seperti:

1. Terjadinya konflik dengan masyarakat sekitarnya pada tahun 2013, di mana masyarakat desa merasa tidak nyaman dengan kedatangan banyak rombongan dan akhirnya pemilik mengambil keputusan untuk menutup sementara kawasan wisata ini, maka sekitar tahun 2014 dibuatlah beberapa ketentuan larangan yang berlandaskan adat dan nilai agama Islam di dalamnya dan wisatawan pun mulai berdatangan. Walaupun hingga sekarang ini dukungan dari masyarakat disana belum sepenuhnya.

2. Akses menuju ke desa Jonjang, di mana wisata ini terletak yang cukup jauh yakni $8 \mathrm{KM}$ dari nagari Pilubang. Jalanan belum di aspal dan terdapat beberapa rute yang hanya bisa dimasuki oleh satu mobil saja. Oleh karena itulah, pengelola sendiri mengatakan bahwa dukungan pemerintah setempat sama sekali tidak ada.

3. Pemilik sendiri yang kurang melakukan koordinasi dengan warga setempat. Seharusnya dengan bekerjasama maka diharapkan kawasan ini benar-benar akan menjadi salah satu destinasi yang sangat menarik untuk dikunjungi.

Kerjasama antara pemerintah setempat dan pengelola sebaiknya dilakukan karena merupakan suatu kesempatan jika hal ini dikembangkan dan bisa dijadikan salah satu destinasi wisata halal kedepannya. Seperti yang dapat dilihat bahwa sekarang ini pun Indonesia dengan tagline-nya 'Wonderful Indonesia' mulai membuka kesempatan adanya destinasi wisata halal dan Sumatera Barat adalah salah satu daerah yang mempunyai nilai jual sebagai wisata halal.

\section{Daftar Pustaka}

Sugiyono. (2007). Memahami Penelitian Kualitatif. Bandung: Alfabeta.

Utama, Edy. (2002). "Adat Basandi Syarak, Syarak Basandi Kitabullah," dalam Ahmad Baso, Plesetan Lokalitas: Politik Pribumisasi Islam. Jakarta: Desantara.

Battour, M. dan Ismail, M. N. (2015). Halal Tourism: Concepts, Practices, Challenges and Future. Tourism Management Perspectives. http://dx.doi.org/10.1016/j.tmp.2015. 12.0082211-9736/@ 2015 Elsevier Ltd.

Geetanjaliramesh Chandra. Halal Tourism: A New Gold Mine for Tourism. International Journal of Business Management \& Research (IJBMR), Vol. 4, Issue 6, Desember 2014, hal. 45-62 (C) TJPRC Pvt. Ltd.

http://ejurnalteologia.co.id/2011/12/traktatmarapalam-adat-basandi-syara.html.

http://payakumbuhkota.go.id/tentangpayakumbuh/geografis/ 